\title{
Lafora disease
}

INSERM

\section{Source}

INSERM. (1999). Orphanet: an online rare disease and orphan drug data base. Lafora disease. ORPHA:501

Lafora disease (LD) is a rare, inherited, severe, progressive myoclonic epilepsy characterized by myoclonus and/or generalized seizures, visual hallucinations (partial occipital seizures), and progressive neurological decline. 